\title{
Morphology and sustainability in the project of public spaces. The case of the historic centre of Viterbo (Italy)
}

\author{
Marco Maretto, Barbara Gherri \\ University of Parma, Department of Engineering and Architecture, Italy \\ marco.maretto@unipr.it | barbara.gherri@unipr.it
}

\begin{abstract}
Anthea Chiovitti
Sapienza, University of Rome

antheachiovitti@gmail.com
\end{abstract}

\author{
Greta Pitanti, Francesco Scattino \\ Sapienza, University of Rome, DRACO \\ greta.pitanti@uniromal.it francesco.scattino@uniromal.it
}

\author{
Nicolò Boggio \\ University of Parma, Italy \\ studioboggioarchitetti@gmail.com
}

\begin{abstract}
The research at the base of the project proposal is based on the idea that a city is, first of all, a body made out of "fabrics": Social, economic, cultural and environmental fabrics that in the physical form of the built environment find their dynamic expression. If the morphological analysis of Viterbo urban fabric has been then the analytical base of the design process, the focus on daily use of urban spaces has been its main analytical goal. But to talk about a shared, efficient, citizen-friendly city, means, at the end of the day, to tell of a sustainable city where Morphology and Sustainability can be part of a unique creative process. That has been our main goal from a methodological point of view. The city is in fact a key resource for the environmental control. The scale of microclimate come into play tighter interactions between design and climate data, improving context environmental conditions, promoting social relations between users and enabling energy-saving-strategies for the creation of a healthy and comfortable urban environment. The joint use of Urban Morphology together with an accurate environmental analysis by GIS Environmental maps and a parametric costs control of design choices for the Economic and Financial sustainability has made possible the design of living spaces, aware and respectful from the identity point of view, efficient from the energetic point of view, but also open and flexible to the changing use conditions of city-life.
\end{abstract}

Keywords: urban morphology, urban design, outdoor comfort, transdisciplinary, Viterbo

To cite this article:

Maretto, M., Gherri, B., Chiovitti, A., Pitanti, G., Scattino, F., Boggio, N. (2020). Morphology and Sustainability in the project of Public Spaces. The case of the historic centre of Viterbo (Italy), The Journal of Public Space, 5(2), 23-44, DOI 10.3289I/jps.v5i2.1280

This article has been double blind peer reviewed and accepted for publication in The Journal of Public Space. (c) (\$) This work is licensed under a Creative Commons Attribution - Non Commercial 4.0 International License https://creativecommons.org/licenses/by-nc/4.0/ 


\section{Introduction and methodology}

The city is, first of all, an organism made of "fabrics". Social, economic and cultural fabrics that find in the physical form of the built city, its streets and its squares, direct and dynamic expression of its vitality over time (Maretto, 2008). The morphological analysis of the urban fabric of Viterbo and its public spaces was therefore the first step of the design action. An analysis that started with the historical-morphological understanding of the walled city (Guidoni et al., 2006) then focused on the daily use of urban spaces and their potential for development and future use to make the centre of Viterbo a sustainable city, suitable for pedestrians and children. It is citizens who ultimately transform the city on a daily basis through their actions and it is always the citizens who guarantee their continuity over time through their ability to "create community" and recognize themselves in a shared identity. Being able to define public spaces capable of generating a diverse use of the city and together, responding to the needs of those who live it was thus one of the main challenges and objectives we set ourselves. One of the tools used for this purpose was the mapping of pedestrian movement flows within the seven squares of the historic centre of Viterbo.

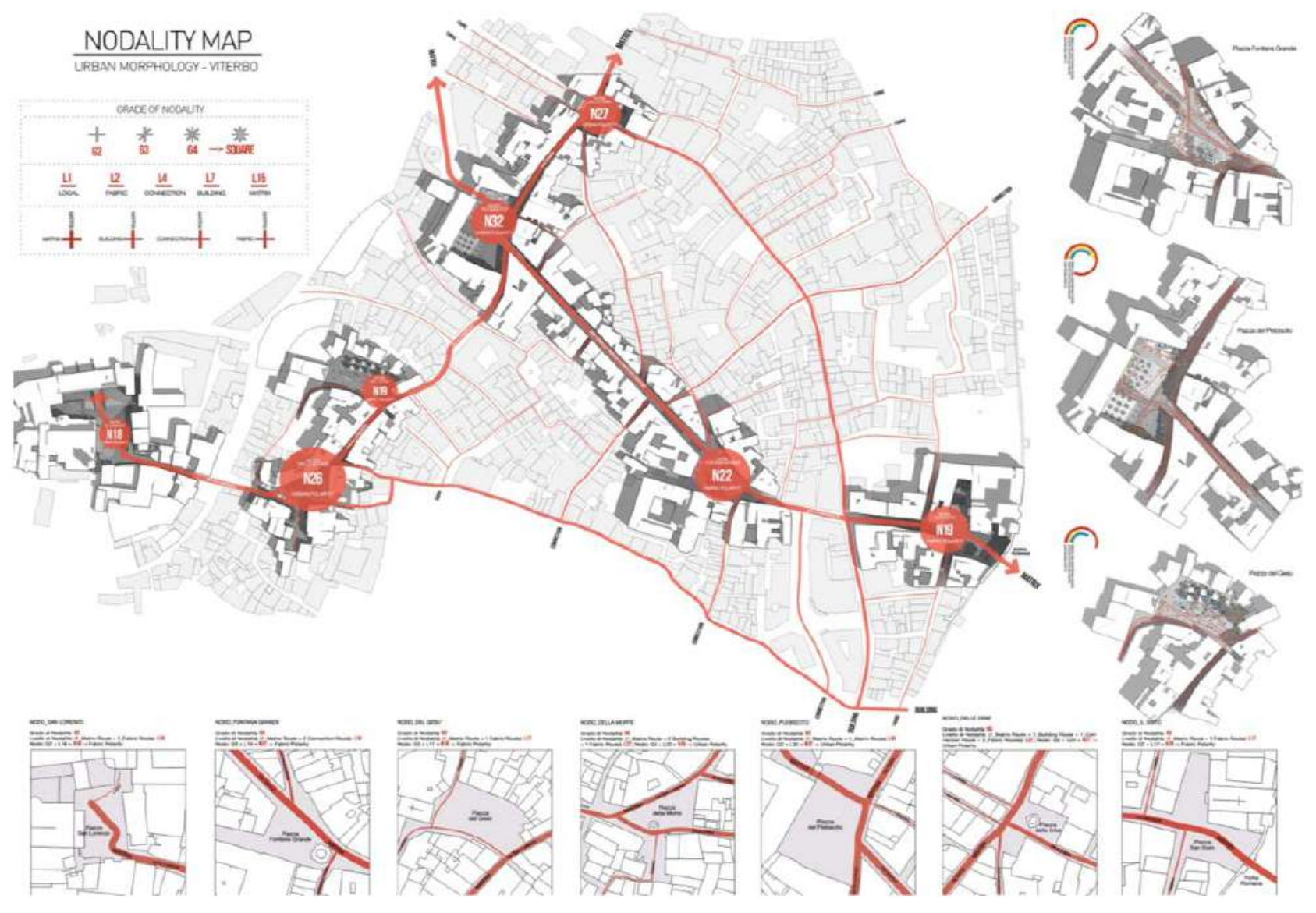

Figure. I. Nodality Survey and Flows Analysis. On the general map the hierarchies of public spaces is given by their different Value of Nodality (N...). A focus on the seven squares (bottom) evidences the Grade and the Level of Nodality of each one in order to obtain their Value. (Source: M. Maretto). 
The observation of pedestrian flows of movement within a public space (Gehl, I987) is, in fact, of great importance for at least two reasons. From a morphological point of view, it allows us to define hierarchies, between paths, urban spaces, functions and other urban features and solutions. These hierarchies, combined with each other, and systematized with the morphology of the urban fabric contribute to the definition of a scale of Nodality Values (Maretto, 2018) able to give us a dynamic map of the morphology of a place both in its physical and immaterial aspects (Figure I). On the other hand, the mapping of daily movement flows tells us how citizens-users use a given public space, providing us with valuable information for its transformation (Figure 2).'

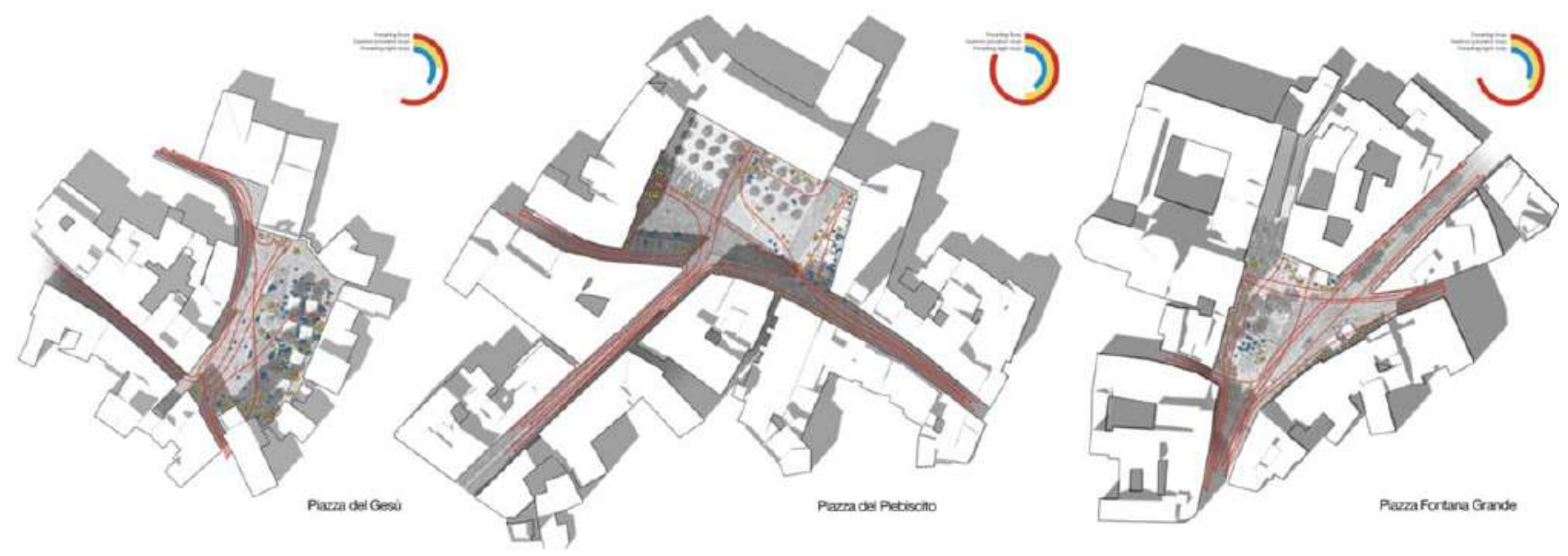

Figure. 2. Pedestrian Flows Analysis of Piazza del Gesù, Piazza del Plebiscito and Piazza Fontana Grande (Source: M. Maretto).

Moreover, these data, combined with the environmental ones, allow us to define a useful analytical basis for the conscious and sustainable design of public spaces. To talk

\footnotetext{
' For each square the prevailing movement flows and the stopover directions were considered. These latter were then divided into diurnal and nocturnal. The new public space is then shown in transparency in order to highlight the relationship between Flows Analysis and the new project. Piazza del Gesù: The main flows go along Via San Lorenzo (Matrix route), from here a secondary flow goes towards one of the main ascents from valley to the ridge. The main stopover directions are instead towards the church (diurnal) and towards a building front characterized by shops and clubs (nocturnal). At the center between these two major directions is a beautiful historic fountain, also catalyzing a part, albeit secondary, of the stopover directions. Piazza del Plebiscito: The three main flows characterize Via Cavour, Via San Lorenzo and Via Roma (Matrix routes). From this trident that informs the entire urban structure of the historic center of Viterbo a secondary flow heads towards the valley bottom (to the northeast). The main stopover directions instead move towards the Palazzo dei Priori (in the center), the Prefettura (on the left) and the Town Hall (on the right). These are mainly diurnal stops with the exception of the Town Hall side where there are some commercial activities open even at night. Piazza Fontana Grande: the mainstream flows along the great axis of Via Cavour (Matrix route), from which two secondary flows go (west and east) along Via delle Fabbriche and Via Aurelio Saffi. The square develops mainly on the left side of Via Cavour, for this reason the main stopover directions are on this side, directed to the church (diurnal) and to a small wall of shops. Here too the presence of a historic fountain catalyzes some of the stops (day and night). Although there are also shops on the right side, the substantial absence of a sidewalk prevents, in fact, the stop.
} 
about a shared, efficient, citizen-friendly city also means talking about a sustainable city, where the concept of sustainability is understood in its widest and most complete meaning. The city is not, in fact, a "zero-emission settlement machine", on the contrary it is a much more complex and vital organism that cannot be reduced to simple performances (Maretto, 2012). In 2016, in order to answer to the Call of the Municipality of Viterbo for the redevelopment of the seven squares of its historic centre, we adopted a methodology combining the themes of urban morphology (MaratMendes, 2013) with those of sustainability. (Figure 3). A square is both a social and an architectural space, is "lived and dreamed" (Levi-Strauss, 1955) and requires a transdisciplinary approach capable of dealing organically with its complexities.

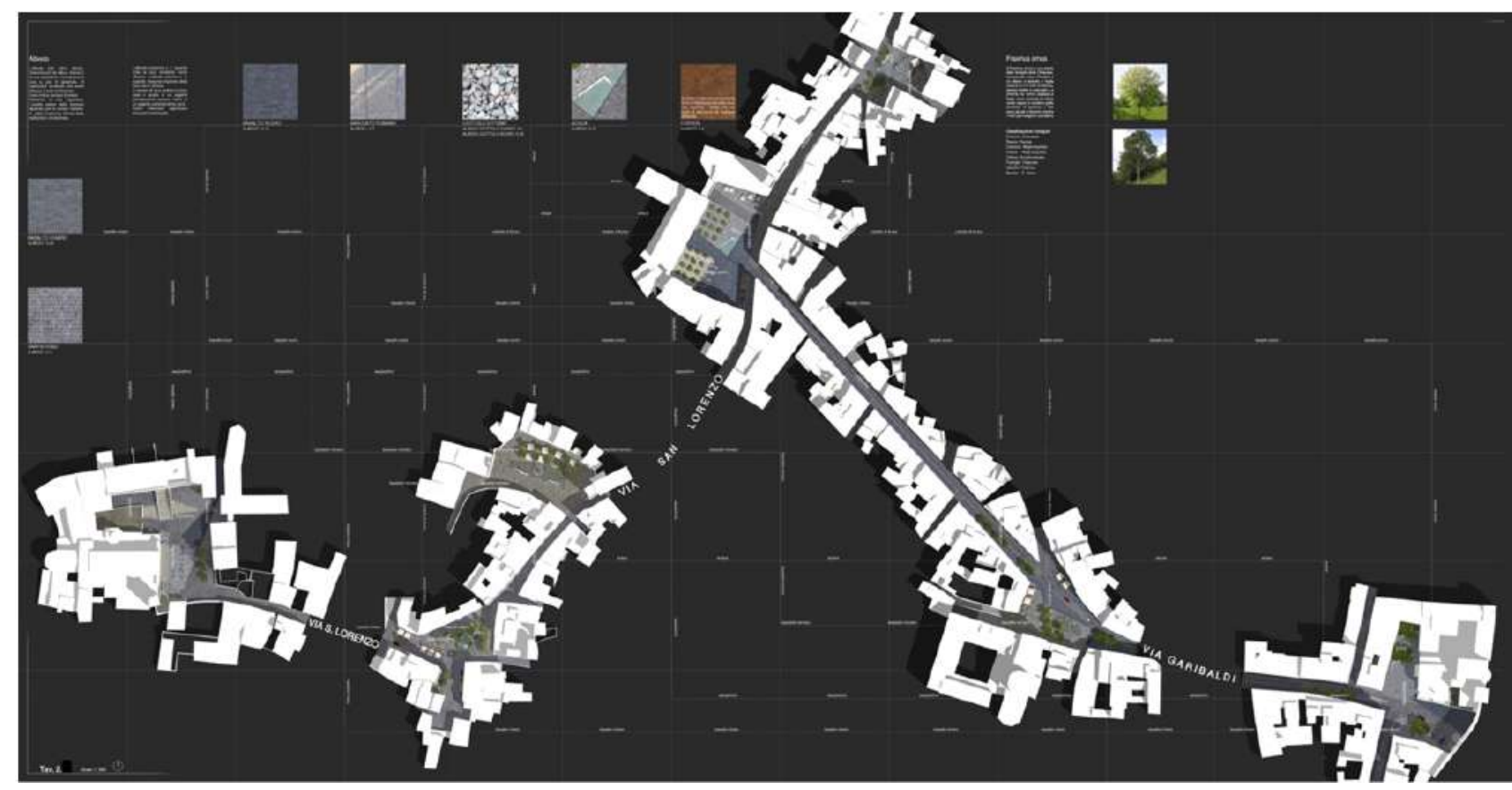

Figure. 3. The project of the seven squares within the historical urban fabric (Source: M. Maretto).

\section{The Environmental Project.}

\section{Microclimate Modelling for Urban Sustainability in public open spaces}

A new paradigm is affirming itself regarding the design of urban open spaces: the climate changes cities, but at the same time it is clear that the city is also responsible for climate change. (Maretto, 2012). In this context, what remains is the disregard of global effects that changes outdoor urban setting and impacts liveability of public open spaces, and in particular the thermal behaviour of dwellers. The climate control of the micro-urban context must be investigated as a lever to enhance energy-efficient and sustainability strategies in case of urban planning and in design for public open spaces. The continuous comparison between the environmental-energetic issue and the morphological-urban topic for urban outdoor space design is a relevant scientific subject, as well as understanding physical-energetical phenomena, on one side, and environmentalsocial facts on the other, helps in defining a correct approach to the question of how to intervene on public urban open spaces in order to pursue a widespread sustainability model. 
In order to achieve the aims of the Paris Agreement, the building and construction sector must decarbonise by 2050 (COP 21 Conference, December 2015) and to meet that target a proper urban analysis should comprise energy efficiency, environmental and social dimensions, in order to reduce greenhouse gas (GHG) emissions. With nations worldwide tackling operational emissions for buildings, a relevant target that now needs to be address is related to urban morphology, called urban Heat Island Effect control, in order to ensure liveability for its citizens to enable a greater level of consciousness regarding environmental sustainability performance.

Recently it has been clearly stated by the UN Environment Programme with the Emissions Gap Report 2019 the embodied carbon reductions can contribute to climate goals in the short term. So far, the attention has been reserved to the total of all greenhouse gas emission results from manufacturing to supply of construction products and materials as well as the construction process itself. But what about the space between buildings, namely the open spaces, the interaction between building envelopes and outdoor environment? Exploring the relationship between climate-based design and city's needs in order to respond dwellers' age, cultural needs, subjective preferences and users' perceptions can be pursued by Microclimatic Sensitive Urban Design MCSUD- (Erell et al., 20I I; Pijpers-van Esch, 2016) to promote sustainable and healthy lifestyles.

Thanks to a MCSUD, designers can intervene in environmental contexts within the densely constructed urban fabric in order to control its main microclimatic attributes (natural and artificial), as a design strategy to address sustainable energy choices for building material selection in this case for the design of public open spaces. Because of parametric simulations, acting on the local microclimate, both in terms of local outdoor air temperature at the street level and in terms of Mean Radiant Temperature (MRT) can be effective in reducing building thermal loads as well as in enhancing users' thermal comfort. In light of these relationships, the contribution of climate-based strategies of the micro-urban space in terms of both indoor and outdoor climate mitigation, energy saving and reduction of GHGs emissions can be assessed by using parametric or dynamic simulation. Thanks to those numerical simulations, the project of Viterbo aims at simulating different configuration of outdoor urban environments and to assess the effects and application of climate sensitive green architecture visions in decision making process in relation to urban public open spaces. Assessing micro-scale urban environments (intended for a typical horizontal resolution from 0.5 to 5 metres and a typical time frame of 24 to $48 \mathrm{~h}$ ) has enabled the analysis of the small-scale interactions between individual buildings, surfaces and materials' property (albedo values).

Since the properties of the materials used within the building envelope play an essential role in defining building performance in terms of thermal comfort and energy savings (Doulos et al., 2004; Aida, 1982; Santamouris, 2004; Taha et al., 1992), establishing new outdoor elements (urban microclimate based approach) can also strongly influence the thermal behaviour and healthy lifestyles for final users. Indeed, as a first effect, for a given outdoor climate the features of buildings' envelope and the selection of urban finishing materials (pavements, asphalts) and vegetation directly affect the heating and cooling load generated to ensure comfort in public outdoor spaces and, conversely, urban local climate has also significant influence on the building envelope and on outdoor liveability, playing an essential role in facing Heat Urban Effect, due to radiant 
and convective heat exchange with external building envelope and outdoor finishing materials (Taha, 1997; Akbari et al., 200I; Synnefa et al., 2008; Santamouris et al., 2008; Santamouris et al., 20II; Morini, 2016).

\section{National and international state of the art and open issues}

Growth of urban populations is estimated to double the global building stock by 2060 (United Nations, 2019). The growing awareness towards the topic of energy savings and the reduction of the environmental footprint has shifted the focus lately from traditional boundaries of building envelopes towards the arrangement of specific parameters and instruments that can be translated to the scale of the urban block, public spaces and transitional areas. The environmental analysis for the urban project needs a rigorous methodology to evaluate the mutual effect of any design project to address the microurban scale design and the related thermal behaviour of building envelopes in relation to human perception. Several academic studies about decarbonisation strategies (Gomez, 2010; Duarte, Shinzato, dos Santos Gusson \& Abrahão Alves, 20I5) highlight that there are no distinct relationships among urban fabrics, building envelope and outdoor open urban spaces. Despite mutual connections have not been fully investigated yet, however they generate a research gap and, consequently, the need for a suitable design method which is offered here. Outdoor thermal comfort is a complex issue, since microclimate and environmental conditions as well as urban morphology strongly affect the thermal load on building facades (Givoni, 1998). Thus, there are several studies that assess human thermal comfort in outdoor areas (Gaitani, Mihalakakou \& Santamouris, 2007; Pizarro 2009). Nevertheless, none of them investigates the repercussion of outdoor design options (i.e. materials choices, green masses disposition and any further bioclimatic devices), on building techniques and design. Furthermore, several tools have been introduced to help designers and practitioners in modelling the outdoor environmental condition such as Rayman and ENVI-met. The rapid increase of tools to evaluate microclimate conditions in early stages of performance site analysis (Naboni, 20I3), however, does not take into account the influence of outdoor design choices on thermal loads for buildings energy demand. Most of the responsibilities are imputable to the proliferation of hyper specialized software that can be supportive during the energy design phase, but often disregard the community engagement to local microclimate as well as the multiplied use of qualitative analysis tools create a significant limitation for urban microclimate based approaches. Along with these premises, the research project for the historical centre of Viterbo aims to define the best practice in order to demonstrate that the use of specific software for microclimatic simulation (such as Autodesk Ecotect, in this specific case design, thanks to its computing and modelling easiness), allows the designer to identify the most suitable technological and architectural choice by considering morphological, technological and environmental knowledge, based on a microclimate based approach. Although Autodesk Ecotect Analysis has been discontinued since 2016, it has been considered in this assessment phase as it seemed very effective and still valid today. It should be noted that key solutions are now available in the Autodesk Revit environment too. Those different software tools have therefore been used in environmental assessments in order to design a climate-based project for each of the seven squares in the Municipality of Viterbo, as illustrated in Figure 4. 


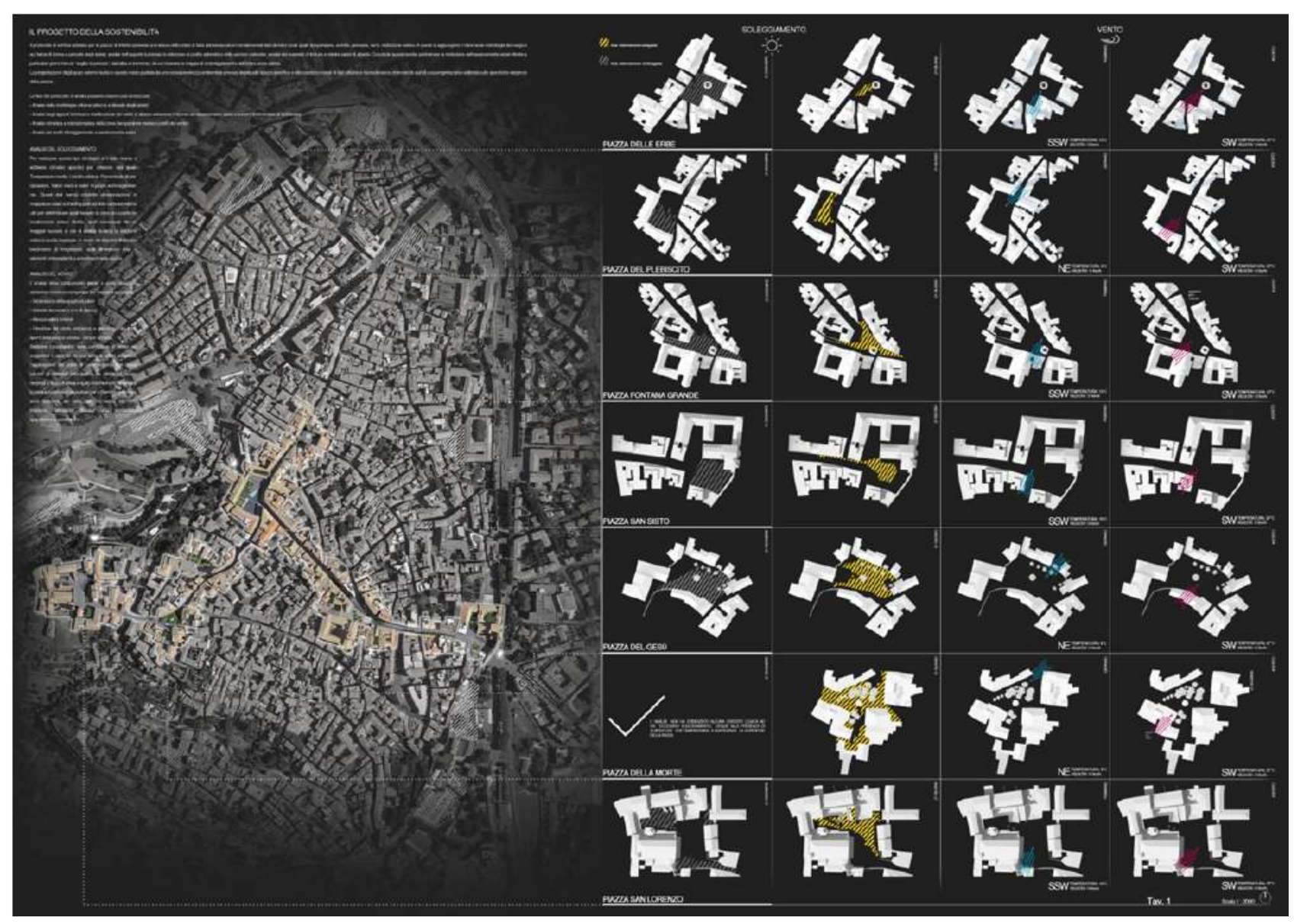

Figure. 4. Examples of environmental analysis and evidence of critical issues within the urban fabric.

(Source: M. Maretto).

\section{Instruments and methods for urban open spaces climate-based design}

When broadening basic pillars of environmental comfort assessment, it is evident that the design of the urban open space should be intended not only for outdoor comfort and liveability for citizens but also for environmental variables associated with wind fluxes, the amount of solar radiation, the albedo values of finishing materials as well as the air temperatures to prevent harmful situations and undesirable thermal loads.

Since cities have proven to be efficient and resilient when facing climate change. Each urban environment can adapt to the effects of climate chance, by scaling up different solutions, mainly based on low carbon and bioclimatic tactics. A climate sensitive approach should consider the city itself as a decarbonizing lever. Several parameters demonstrated to be effective means when reducing temperature and GHG emission, by taking into consideration: topography and elevation; ground cover and vegetation; wind distribution among buildings and roads; presence of green mass; presence of water bodies; urban geometry (orientation of the streets and urban form) and Albedo values (Gherri, Maretto, Guzhda, Motti \& Zannetti, 2018). The microclimatic environmental analysis used for the case study of Viterbo allowed the authors to control and manipulate the environmental conditions for a given urban environment in 
order to define a tailored urban design response with the primary goal of mitigating potential negative effects (i.e. relieving excessive solar irradiation on horizontal surfaces) and to exploit the positive ones (i.e. channelling wind breezes to cool down outdoor areas), to ensure optimal comfort conditions supporting designers with an interactive and comprehensible analysis procedure. Therefore, the aim of the present paper is to prove that urban morphology and sustainability issues can achieve improved outcomes for sustainable urban projects, combining microclimatic-environmental variables and subjective comfort metrics. They shall be applied to the urban blocks, public spaces and transitional areas.

A survey to define an appropriate range of sustainable and comfort indexes has been preliminarily focused on a review of the indices and metrics that are currently used to measure the environmental sustainability of the open spaces as well as subjective comfort indexes for final users. Therefore, the existing indexes were analysed to measure perception of outdoor comfort of human subjects. Among the parameters that contribute to outdoor human comfort, temperature is the most important factor when defining the quality of an outdoor space. Thermal comfort is a condition in which the user prefers neither warmer nor cooler temperatures, i.e., the ideal temperature. Outdoor thermal comfort (Fanger, 1970) is a complex issue to be assessed since microclimatic and environmental conditions as well as urban morphology strongly affect the perception of outdoor thermal comfort.

Currently there are several studies on assessment human thermal comfort in outdoor areas available (Cheng et al., 2007; Ali-Toudert \& Mayer, 2006; Nikolopoulou \& Lykoudis, 2006; Tseliou et al., 2010). They can be used to assess outdoor thermal comfort for dwellers and include the following: Predicted Mean Vote (PMV) (Humphreys, 20I0) and Standard Effective Temperature (SET) (Gagge, Stolwijk \& Nishi, I97I) which are originally proposed for indoor assessments, Physiological Equivalent Temperature (PET) (Matzarakis \& Amelung, 2008) and Universal Thermal Climate Index (UTCl) (Matzarakis, Mayer \& Iziomon, 1999) for outdoor comfort assessments.

Starting from the Predicted Mean Vote (PMV), introduced by Fanger (1982), Predicted Percentage Dissatisfied (PPD) state the percentage of users who are not satisfied with individual PMV values from a thermal point of view. Nonetheless, PMV and PPD were primarily intended to evaluate thermal comfort condition for any indoor environment and, therefore, are not appropriate for outdoor zones assessments (Kinouchi, 200 I), mainly due to overestimation of the thermal sensation in the warmer climate and inversely in colder condition. The Predicted Mean Vote PMV assesses the well-being of individuals and considers both the physical-climatic variables and the subjective variables. Therefore, the thermal sensation can vary from one individual to another according to their sensitivity. PMV considers air temperature (Ta), Mean Radiant Temperature (MRT), Relative Humidity (RH), wind speed and the subjective variables that depend on the individual clothing (measured by "clo") and the metabolic activity performed (measured by "met"). On the contrary, it defines the percentage of users dissatisfied by the thermo-hygrometric conditions. According to the ISO 7730 the 10\% (ISO 1994) of users is the maximum limit of dissatisfaction that can be acceptable to define a comfortable environment. As for the ASHRAE 55 standard, the limit shifts to $20 \%$ (ASHRAE 2004). On-site thermal environments can be assessed by using the Universal Thermal Climate Index (UTCI). The UTCl equivalent temperature for a given combination of wind, radiation, humidity and air temperature is then defined as the air 
temperature of the reference environment that produces the same strain index value. Physiological Equivalent Temperature (PET) (Mayer and Höppe, 1987) is the index for the steady-state method in outdoor spaces' evaluation. Since PET can take into account the impacts of short-wave and long-wave radiation fluxes on human energy balance, PET is considered as one of the most reliable indexes especially in semi-enclosed spaces (Mayer and Höppe, 1987; Gulyás et al., 2006).

\section{Environmental Analysis of Viterbo historical urban fabric}

The authors have initially assessed the outdoor conditions of the project area by choosing some environmental variables with respect to which the numerical analysis has been conducted (Autodesk Ecotect). The main parameters and their associate variables assessed in the Viterbo project had to include some key elements that help in identifying the generalisability of a micro space and its ability to correspond to multiple dimensions in a microclimatic scenario within the urban precinct (Cutler, 2008).

The evaluation has been performed during four thresholds (March 2 I st, June 2 Ist, September $2 \mathrm{Ist}$, December $2 \mathrm{I}^{\mathrm{st}}$ ) and during three different times (i.e. morning, early afternoon and one hour before sunset).

The environmental parameters that have been considered for the calculation are:

- Air temperature, which is used to investigate the level of comfort, based on the vertical difference of temperature, measured at ankle and head height. Those heights are the most significative ones to depict thermal comfort. Assuming a $3^{\circ} \mathrm{C}$ temperature difference as the optimal range to fall within the comfort range, the data assessed on three annual thresholds detected some zones with a vertical temperature difference that were higher than the maximum acceptable threshold.

- Relative Humidity has been analysed in relation to the air temperature and calculated at one meter height from the ground surface.

- Wind flux is an essential data point for the identification of potential discomfort areas. In case of detection of turbulent areas, weak mitigation interventions on the open space scale could be applied in order to avoid canyon effects or other related phenomena. Therefore, two different heights, significant for design purpose, have been evaluated: ankle height and head height which are useful to understand the influence of the wind on the user's sensitive areas.

- Solar radiation, global amount of solar radiation calculated by software returns data from direct, diffused and reflected solar radiation. Areas of excessive irradiation can be spotted all year round. Using this data, designers could foresee how to better design finishing materials.

This data has led to further elaborations of maps that are considered to be useful for setting up adequate environmental mitigation strategies from the early stages of the project onwards. A fundamental tool for this purpose was the use of GIS (Geographical Information System) software in order to guide all the design choices in an integrated and efficient manner (Figures 5-6). 


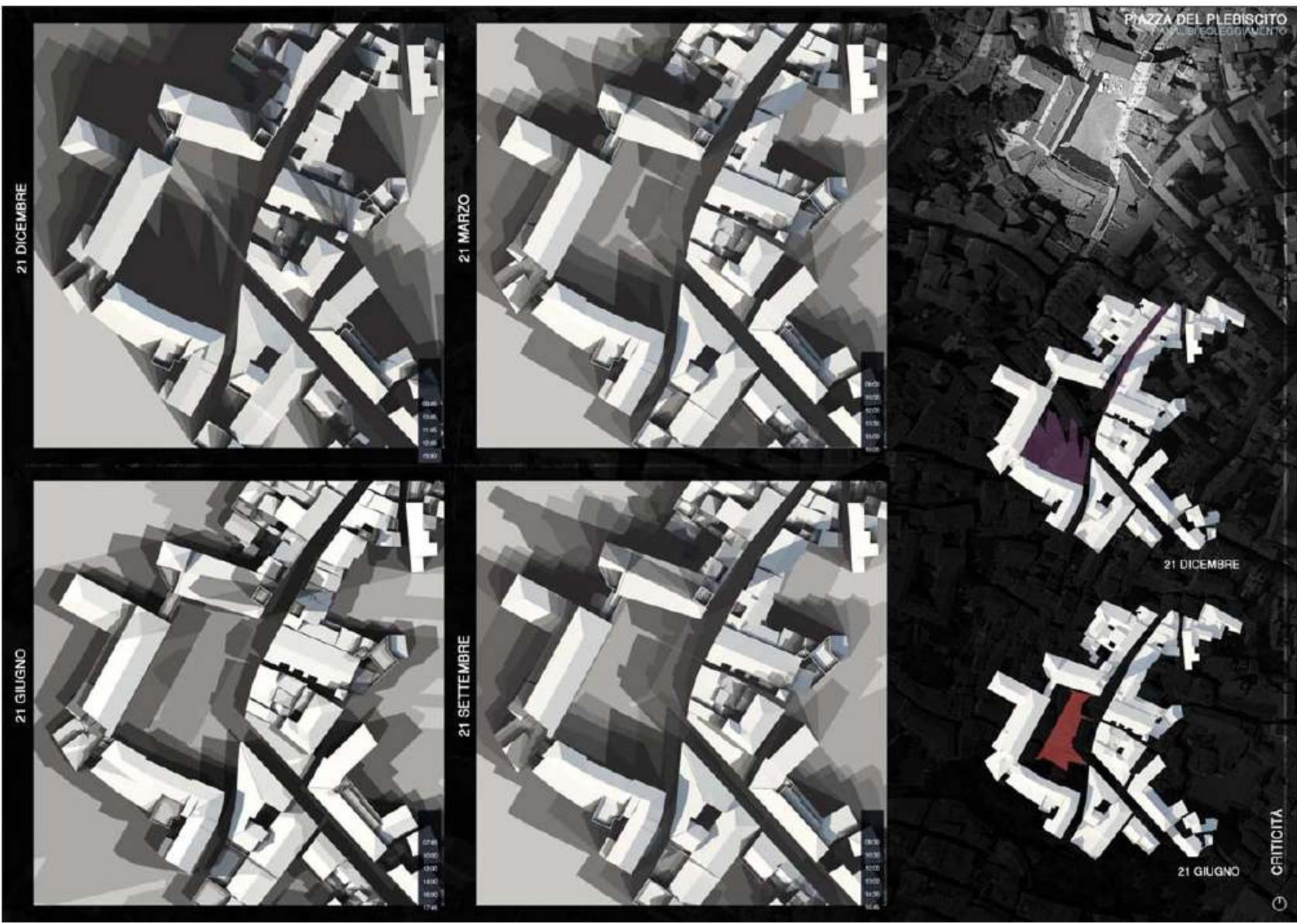

Figure. 5. Piazza del Plebiscito: Shadows Overlapping. The analysis shows a moderate winter shading (December 21 st threshold) in the lower part of the square and an excessive summer sunshine (threshold of June 2 Ist) in the central part. (Source: M. Maretto).

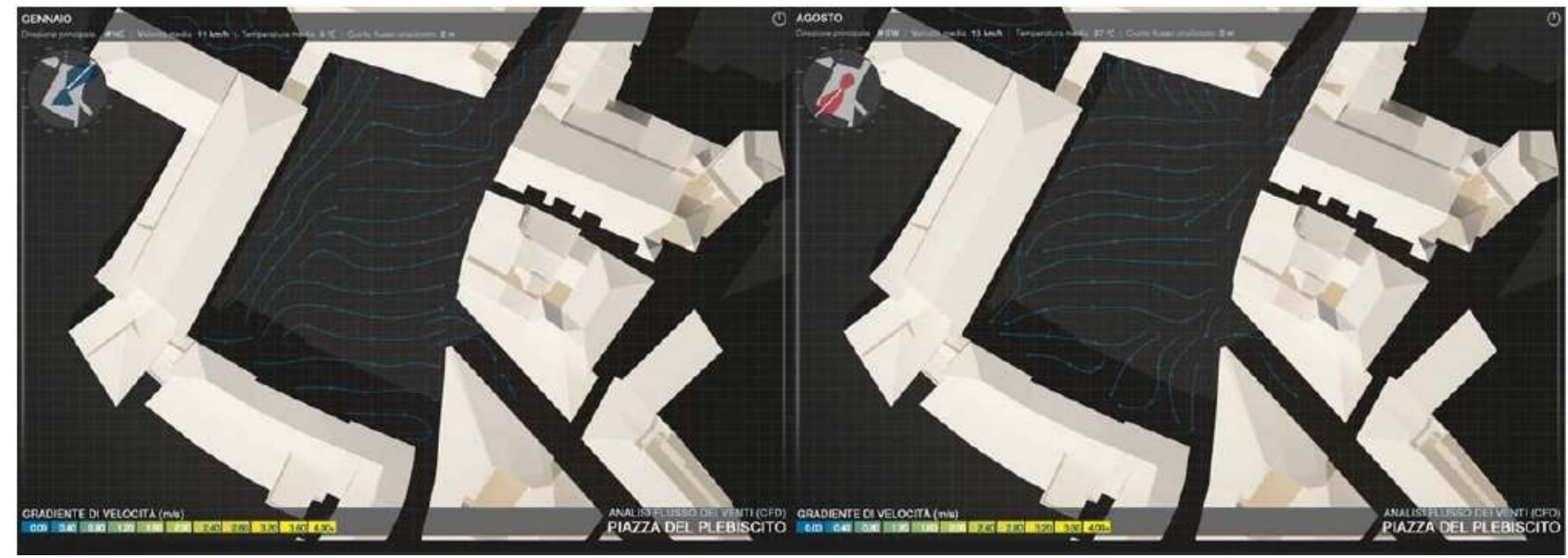

Figure. 6. Piazza del Plebiscito: Wind Flows Analysis. The analysis shows a strong winter ventilation (January threshold) both in SouthWest-NorthEast direction and in West-East direction and a warm summer ventilation (August threshold) in East-West direction. (Source: M. Maretto). 
Particular attention was also given to the presence of vegetation and water as important bioclimatic indicators in regulating temperatures, favouring in particular passive cooling in hot weather. Moreover, the presence of deciduous trees has allowed containment of the solar radiation in hot weather and the possibility of obtaining solar gains in the cold season. However, vegetation and water also have the ability to favour the formation of night and morning breezes that contributes to a gain in air quality and increases outdoor comfort. Finally, the evaluation of finishing materials through the choice of their environmental compatibility and their albedo value completes the environmental analysis in support of sustainable urban design. The proportion of solar radiation (direct and diffuse) that is reflected by the ground and surrounding objects (albedo) can, in fact, be increased or reduced through the use of suitable materials, encouraging the use of open spaces that would otherwise be excessively exposed to solar radiation or too dark and cold to accommodate outdoor relational spaces (Figures 7-8).

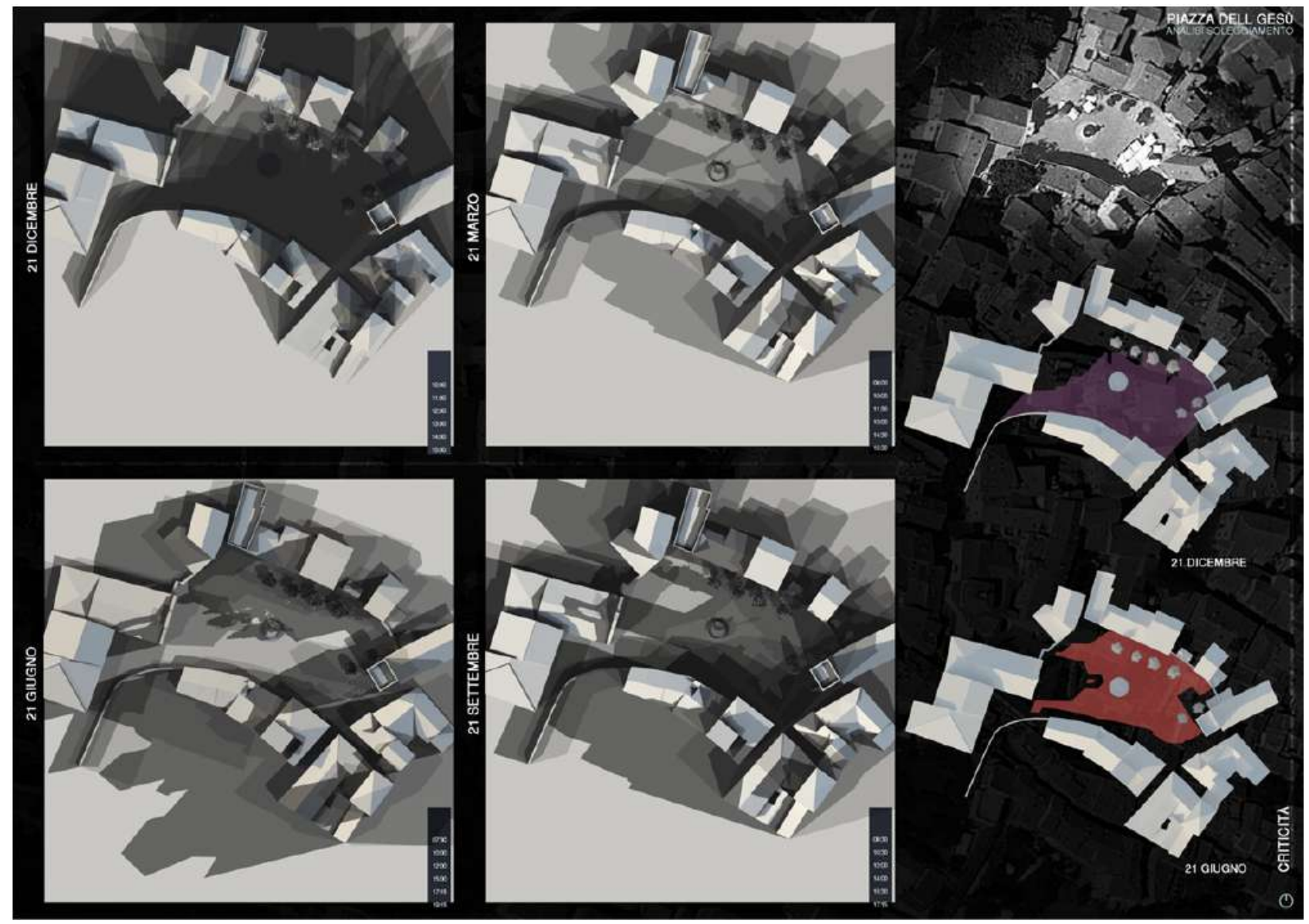

Figure. 7. Piazza del Gesù: Shadows Overlapping. The analysis of sunshine shows the presence of two critical thresholds. The first, on December 2 Ist, sees the square completely shaded, the second, on June 2 Ist, sees it entirely sunny. In the remaining months the values are essentially weighted.

(Source: M. Maretto). 


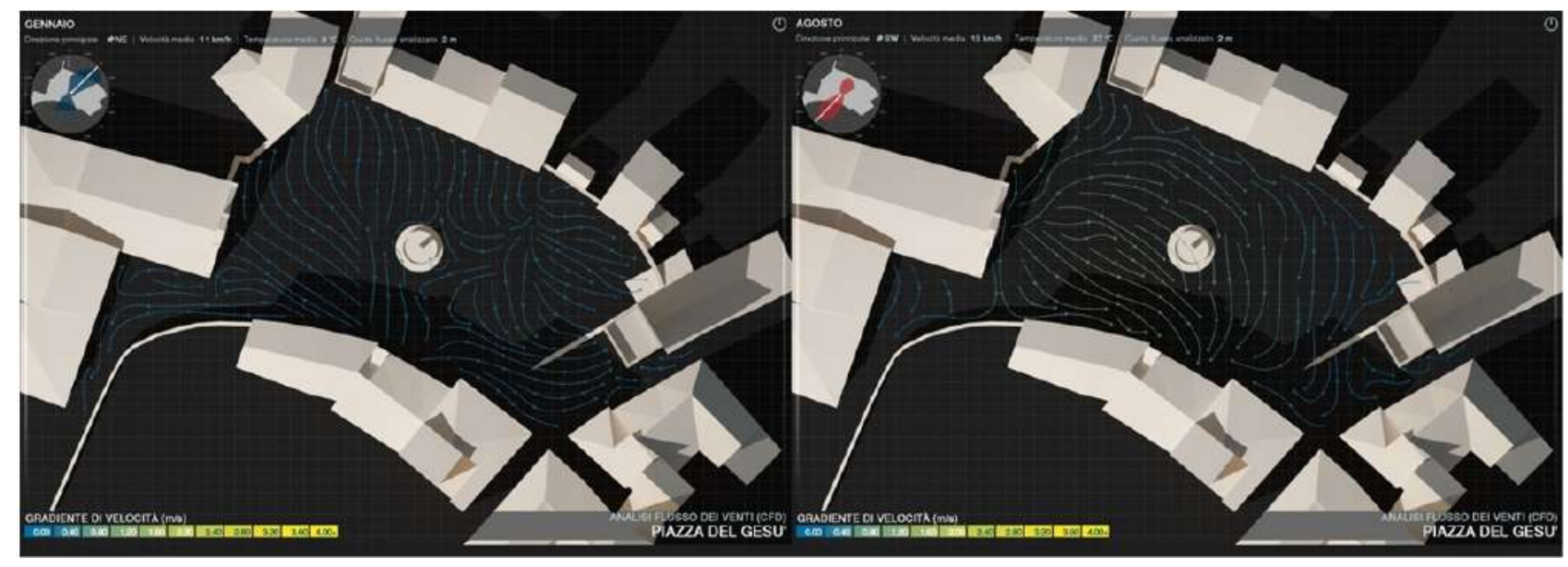

Figure. 8. Piazza del Gesù: Wind Flows Analysis. The analysis shows that in the winter months (January threshold) there is a prevalence of cold winds in the South-North direction, while in the summer months (August threshold) a prevalence of hot ventilation flows in the West-East direction. (Source: M. Maretto).

To complete the environmental assessment, attention was paid to the applied choice of lighting bodies. Lighting had received several functions including different lighting effects or different scenarios depending on prevalent night use of the squares as well as to contain energy consumption. The choice of LED bodies was combined with the use of devices to detect the presence of moving subjects in order to differentiate public lighting on two levels.

On the one hand, lighting fixtures have been designed to guarantee minimum night-time illumination, on the other a second level of lighting fixtures has been designed. The latter, at lower altitudes, are activated in the presence of bodies in motion ensuring always diversified lighting scenarios. All this goes to the advantage of considerable savings in public lighting and avoiding night-time over-illumination, the "light pollution" of the historic city (Figures 9-10).

Consideration of thermal comfort conditions in outdoor micro-urban spaces as one of the mean factor can be deployed as part of a conscious outdoor design practice but has lately proven to be complex and challenging. Nikolopoulou, Baker and Steemers (200I) revealed that while microclimatic parameters strongly influence thermal sensation, they cannot fully account for the wide variation between objective and subjective comfort evaluation. Therefore, considering thermal sensation for outdoor space indexes, along with climatic indexes, is vital for better address design choice and in order to assure comfortable outdoor space conditions for end users. Nevertheless, the actual situation in software capabilities is still limited. It is advisable to deploy instruments in the early stages of the design phase in order to provide a predictive feedback about the foreseen solutions with reference to outdoor thermal comfort for end users.

Furthermore, to get to a performance optimization in terms of environmental micro urban design for outdoor space, practitioners need to understand that an early design stage evaluation with regards to outdoor conditions can impact significantly the way micro urban scale work. This is the ultimate aim of achieving a coherent, rational, liveable and environmentally conscious outdoor urban public spaces (Maretto, 20I4). 


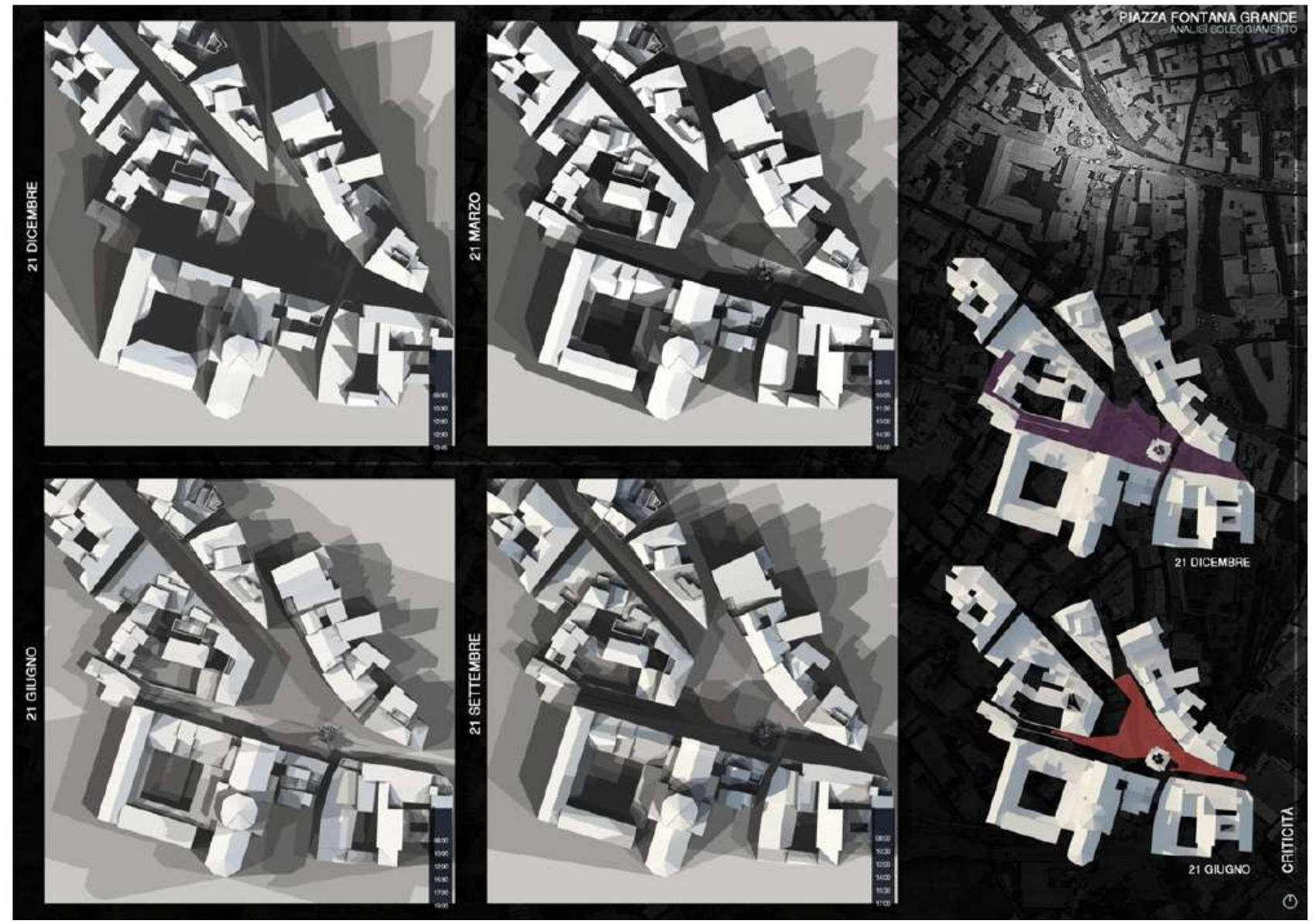

Figure. 9. Piazza Fontana Grande: Shadows Overlapping. The analysis shows how the entire square is subjected to excessive shadowing in the winter season (December 2 Ist threshold) and to excessive sunshine in the summer (June 2 Ist threshold). The first is concentrated above all in the lower part of the square, the second in its central areas (Source: M. Maretto).

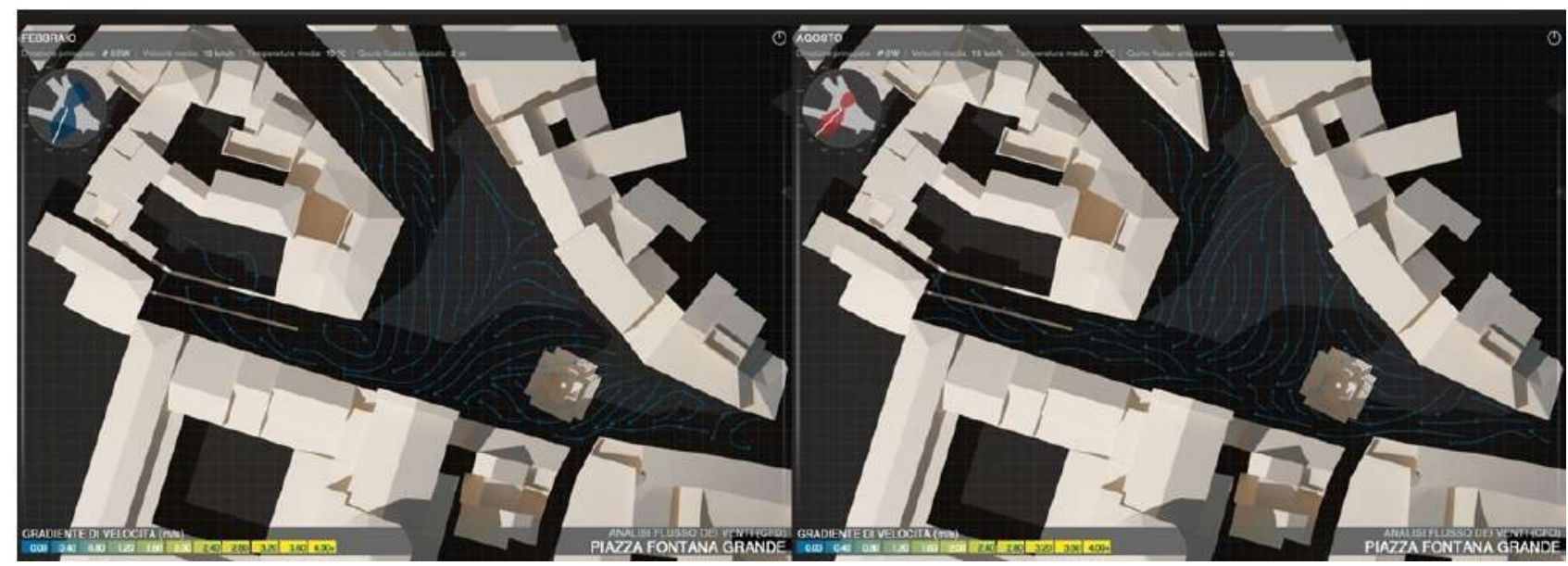

Figure. 10. Piazza Fontana Grande: Wind Flows Analysis. The analysis shows that, in the winter season (February threshold) there is an excessive ventilation in the North-South direction while, in the summer season (August threshold), a number of warm East-West flows are added (Source: M. Maretto). 


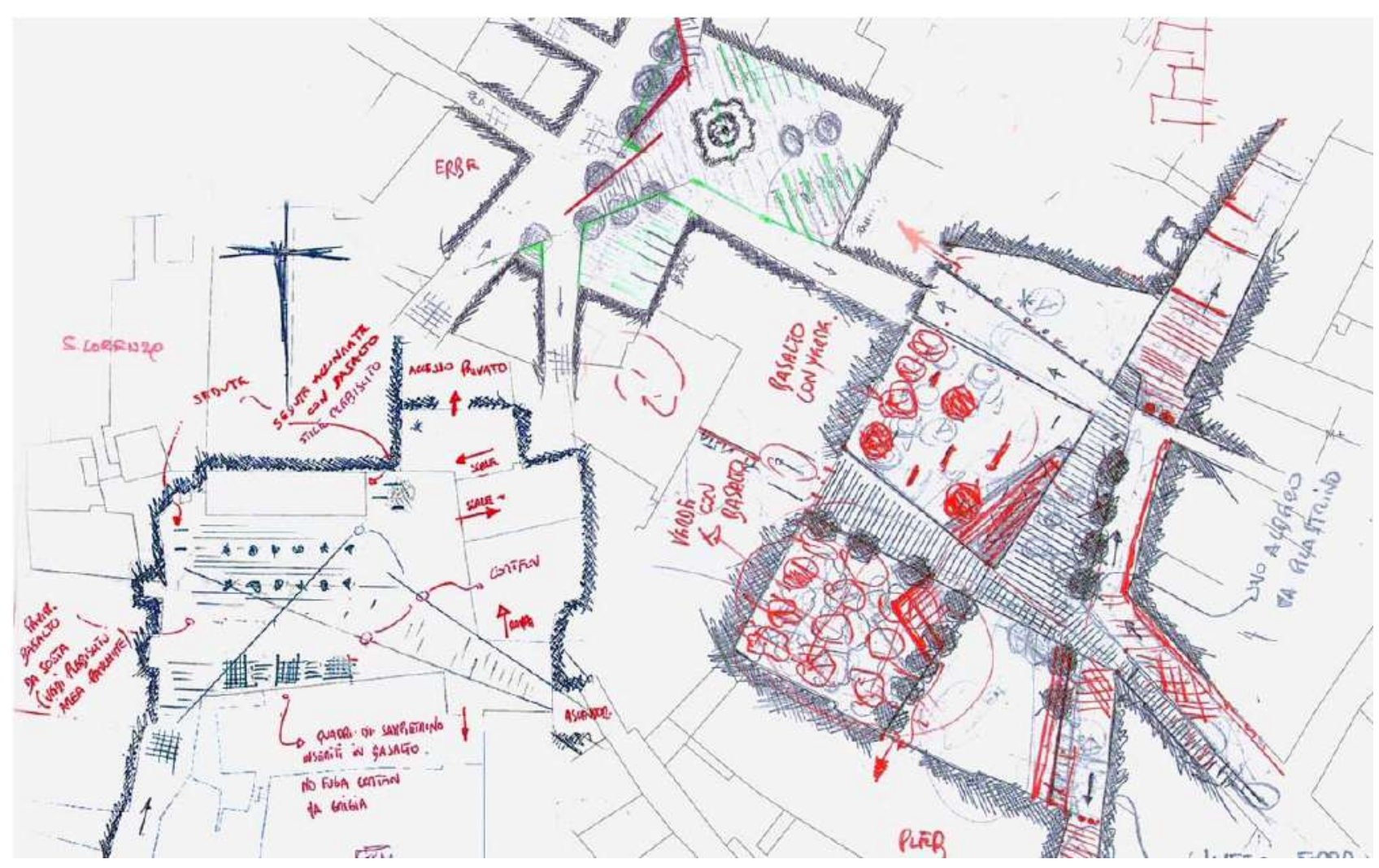

Figure. I I. Design sketches of Piazza del Plebiscito (right), Piazza delle Erbe (middle) and Piazza San Lorenzo (left) (Source: M. Maretto).

\section{The Architectural Project}

The project aimed to research seven squares, and evidently follows the results of the analyses carried out at the morphological-environmental level. On this basis, some guidelines have been chosen for the design of the squares to be further developed according to the specific character of each public space. In fact, we felt it was extremely important to preserve the identity of the individual squares within a unitary organic design. Thus, common to all projects is a distinction of public space in preferential traveling areas and rest areas. The latter, in particular, were then hierarchized and differentiated according to the needs found in the different squares. More "structured" rest areas have been designed in correspondence with the main monuments through a paving in clear basalt slabs, the realization of fixed travertine shaped seats and where there is not already an historical fountain, equipped with a mirror of water (Figure 12). The presence of water immediately seemed to us to be a relevant identity indicator as well as an effective instrument in its own right to control the microenvironment. Concerns remain with those areas that play a particular urban role but are not directly affected by buildings of public importance. Here, too, the use of a light basalt denotes their eminent pavement role, but the design of simpler fixed seating, shaped like a parallelepiped and the absence of the water mirror, clearly hierarchizes them with respect to the previous ones. In these cases, the insertion of lines of turf will be foreseen, between the joints of the basalt, to underline the more "local" character of the public space (i.e. Piazza del Gesù) (Figure 13). 


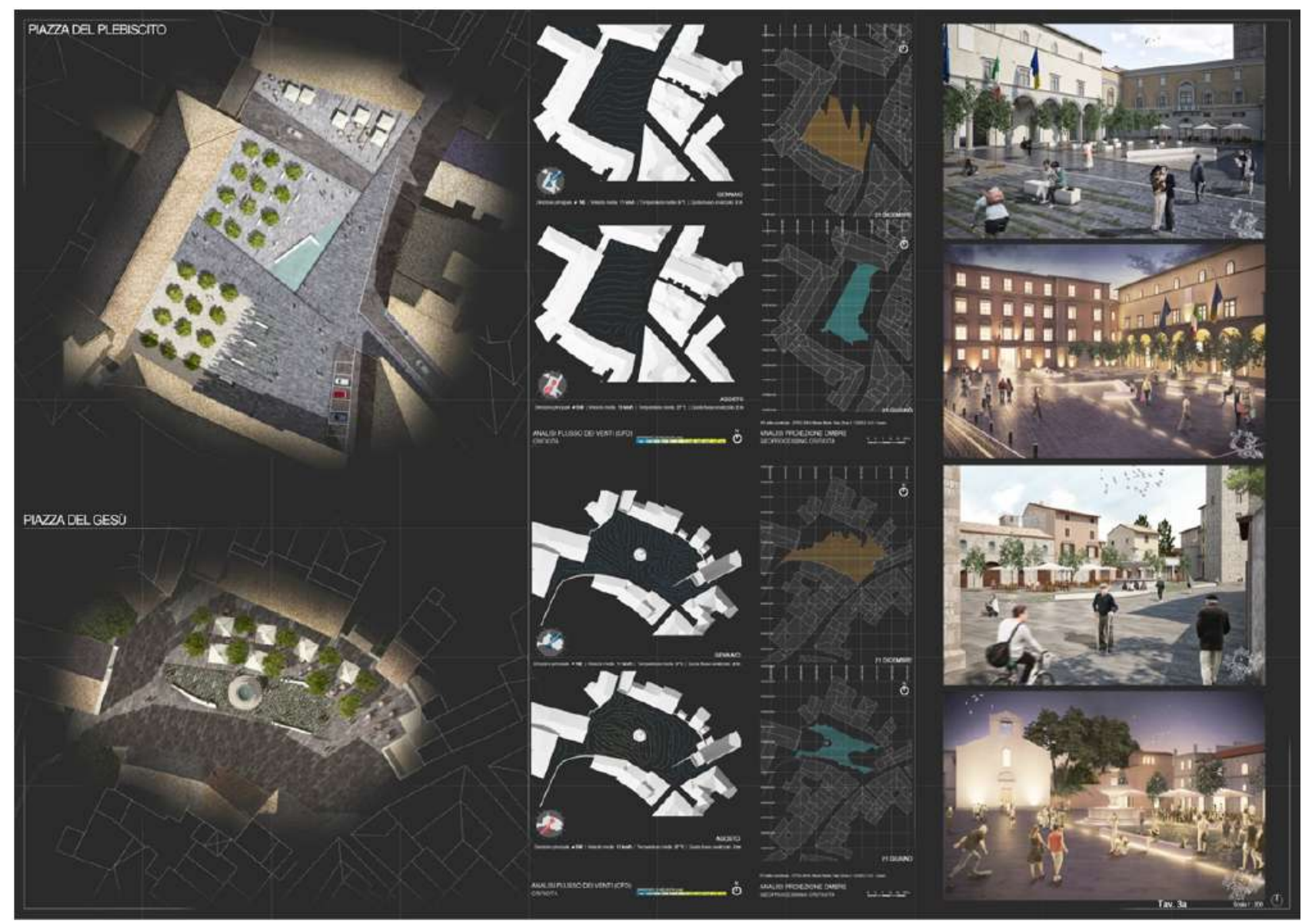

Figure. 12. Piazza del Plebiscito (above) and Piazza del Gesù (bottom): Architectural project and Environmental Analysis (Source: M. Maretto).

Finally, special areas for the dehors have been designed by inserting longitudinal Corten elements inside the basalt flooring (between one slab and another) in order to identify, in a visible but not dominant way, the ambits intended for commercial spaces (bars, restaurants, etc.). These areas receive a role of the overall square design and integrate themselves perfectly with the architectural and functional qualities of the public space, even in the event of temporarily absence of dehors.

The main pedestrian routes are designed with the use of dark basalt slabs to facilitate their visual perception and avoid coming into conflict with the rest of the pavement. As a rule, the direction of the textures of the slabs (both of the paths and of the squares) is set to favor the accessibility and use of the square and when necessary, it is further strengthened by the presence of thin Corten lines (i.e. in Piazza San Lorenzo and Piazza delle Erbe).

In order to avoid cutting the slabs as much as possible to facilitate their installation and containing the relative costs, the points of convergence between different textures were treated with the insertion of small (not stabilized) stone pebbles (Figure 14). These areas contribute to the increase the permeability coefficient of the square and correspond to the areas through the introduction of specific tree species, generating "natural" systems of environmental control that are well integrated in the overall urban design. These trees, mainly Fraxinus Onus and Tilia Platy-phyllos, on the one hand, 
follow the bioclimatic and livability requirements of the public space, and on the other hand, enhance the historic compactness of the building walls.

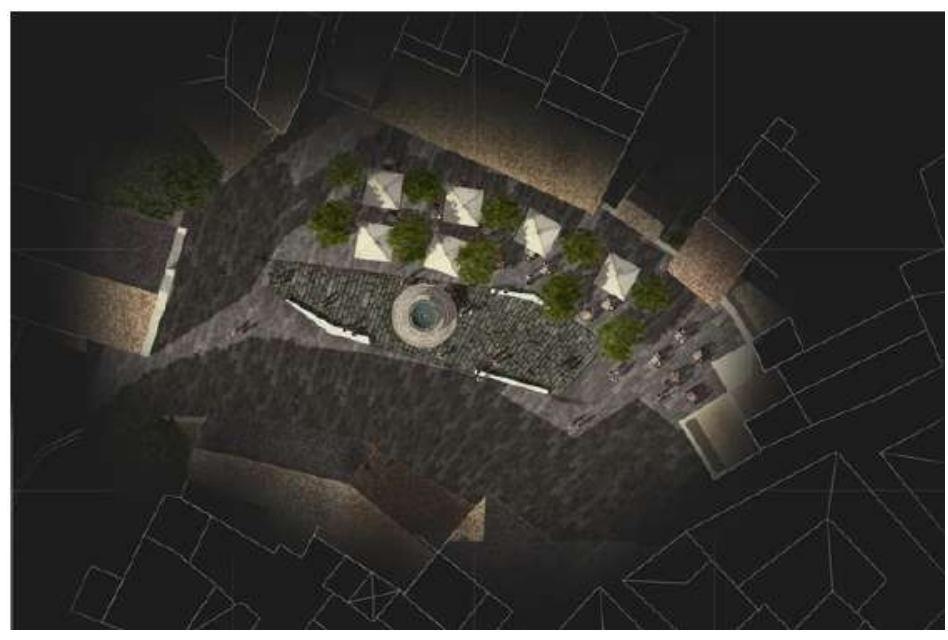

Figure. 13. Piazza del Gesù detailed view. ${ }^{2}$ (Source: M. Maretto).

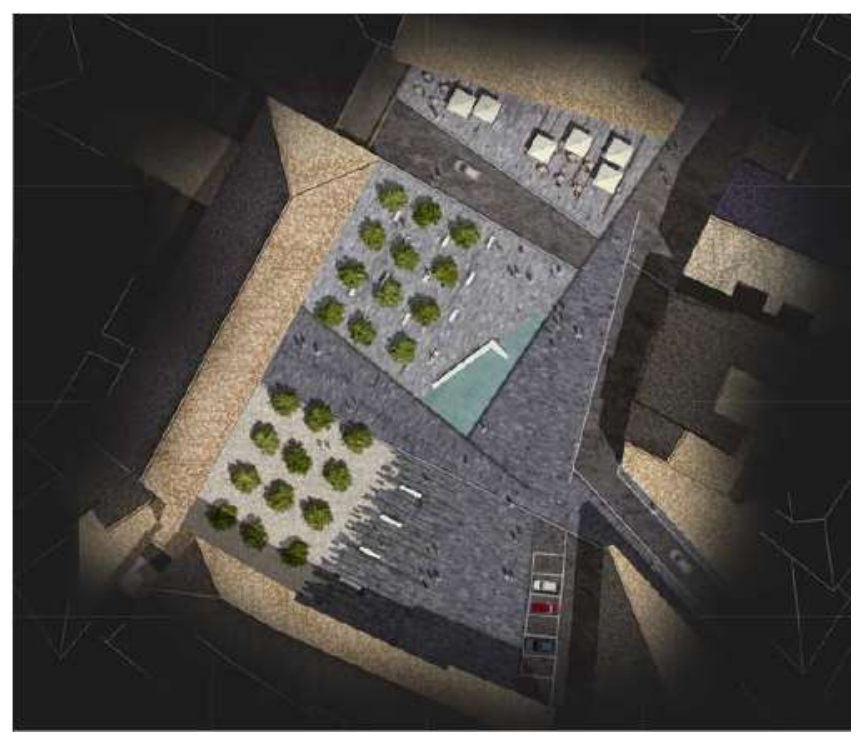

Figure. 14. Piazza del Plebiscito detailed view. (Source: M. Maretto).

\begin{abstract}
${ }^{2}$ The design theme is, in this case, to give identity to the small square by putting the few elements that characterize it into a system. The analysis of pedestrian movement flows told us of a mainly pedestrian square dedicated to leisure and free time, with a tangent path that branches off from the Matrix route on Via di San Lorenzo, heading north, to reach the valley floor. The Chiesa del Gesù and a historic fountain divide these two areas. The environmental analysis also highlights the presence of excessive summer sunshine and cold south-north winds in winter and warm west-east in summer. The choices then led to the creation of a tree-lined front (cedar leaf trees) on the north side in order to protect the commercial areas from the winds and to ensure good summer shade. Thin lines in Corten follow the course of the basalt stone slabs and trees in order to strengthen the perception of this side of the square. At the same time, a basalt pavement, interspersed with green lines, was used to characterize the central area around the historic fountain, though leaving the visual axis of the church façade free as a thematic element of the square.

${ }^{3}$ The first design theme was to integrate the three great Matrix routes of Via San Lorenzo, Via Cavour and Via Roma into a large urban design capable of giving identity to what is, without doubt, the most
\end{abstract}


As with many wonderful French, Spanish and Italian historical centers (Avignon, Arles, Barcelona, Valencia, Cortona, Lecce, Catania and many others) the arboreal element is carefully selected and positioned so as not to overpower the view of the urban fronts but, on the contrary, to enhance the value of the square as a civil space par excellence (Maretto, 2019) (Figure 15).

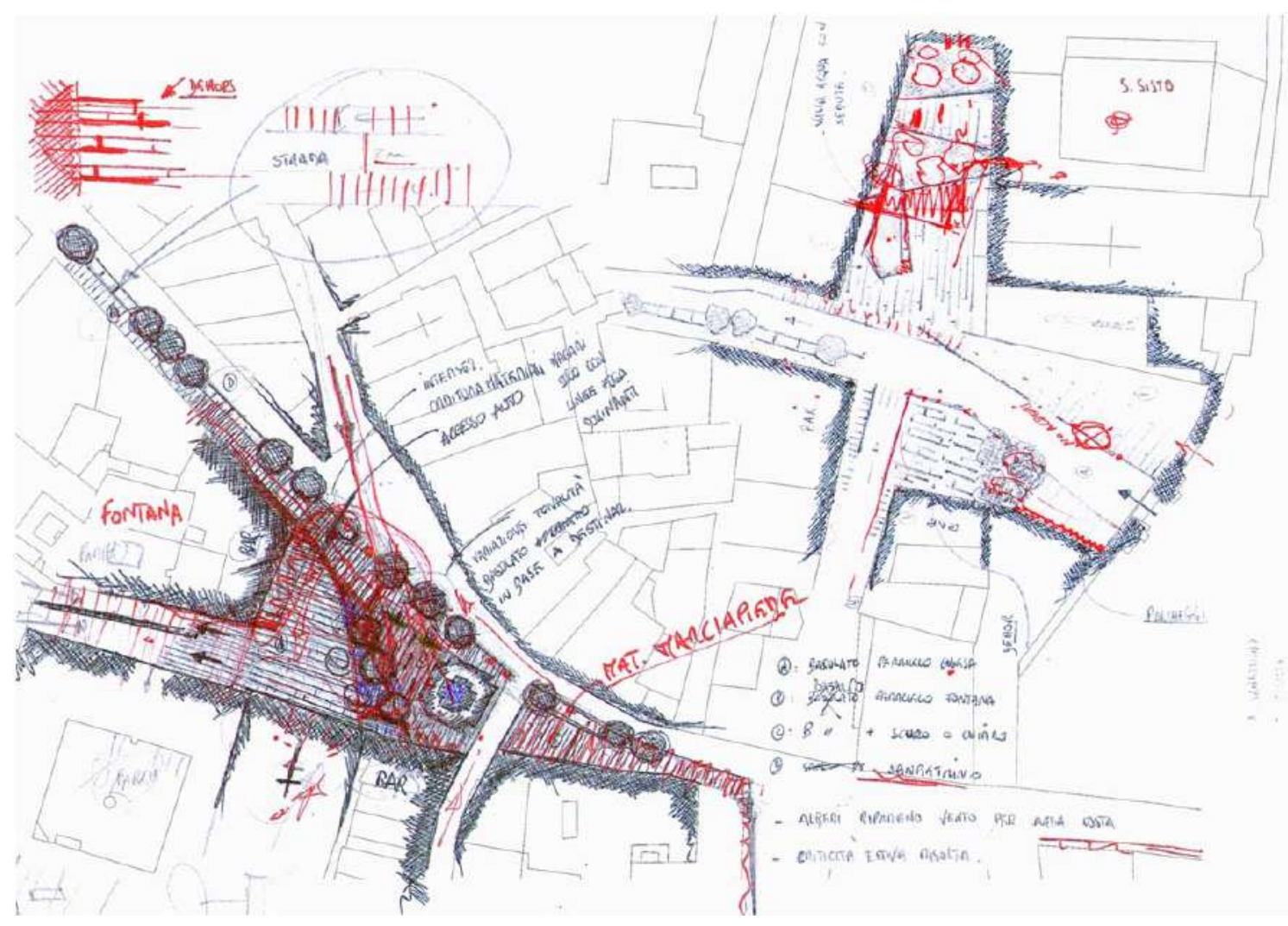

Figure I5. Design sketches of Piazza San Sisto (right) and Piazza Fontana Grande (left) (Source: M. Maretto).

important square in Viterbo. For this purpose, the same material was chosen (in different shades) to highlight the pedestrian areas and another for the driveways, placing a large fountain at the intersection of materials and axes. The second design theme was to give a "logical order" to the spaces of the square. To this end, the analysis of the Pedestrian Flows was decisive. On the one hand, it showed us what the main paths of pedestrian movement were. On the other hand, it highlighted the need to hierarchize and identify better the rest areas which is today very chaotic. Without prejudice to the fundamental connection, physical and perceptive, with the large Palazzo dei Priori, it was thought to create a pertinence space "de 'Priori", in light basalt, in order to encourage permanence in front of its large porch and reinforce its prospective value. Next to this, a paved space was then designed, with green lines between the dark gray basalt slabs, to mark the parterre of the Palazzo della Questura. In parallel, an area characterized by thin lines of Corten and light basalt slabs has been placed to reinforce the commercial spaces on the side of the Town Hall. The third design theme taken into consideration was obviously the environment. The analysis has shown us the incidence of a strong summer sun and of annoying winter winds towards south west- north east. For this reason, in addition to the morphological choices, three rows of trees have been thought. On the one hand, they protect the square from excess winds and summer sunshine. On the other hand, they enhance the role of a great urban backdrop for Piazza del Plebiscito and the Palazzo dei Priori. The fountain is, in turn, an important environmental mitigator helping to improve the levels of outdoor comfort throughout the square. The project of the square combined the analyzes carried out on a morphological level, of daily use and environmental in a single urban design. 
The different combination of all these elements, in the different squares, depends on the morphology, the use and the urban role that every public space exerts within the city as well as by the case specific environmental needs.

For this reason, it was considered necessary to intervene as little as possible in Piazza San Lorenzo, limiting the project to the study of the landing of elevators and the placement of a fountain with controlled artistic splashes in the centre of the public space. For Piazza del Plebiscito the intervention was more consistent, both for the considerable size of the urban space, for its significant civic role as it is the most important urban centre of the old town. The result is a plurality of solutions within a basic unitary design able to return, from time to time, the individuality of each specific urban environment without ever losing the sense of belonging to the common historical identity of Viterbo (Figure 16).

From the point of view of vehicular traffic and flow, we suggested the adoption of a Restricted Traffic Area for the entire historical center, using (and implementing) a large parking area outside the city wall. In any case, all the roads are kept in basalt blocks whose texture varies, from diagonal to orthogonal, depending on the importance of the road. Only a few "short term" parking areas have been planned at Piazza San Sisto, Via Garibaldi and Via Cavour (near Piazza Fontana Grande), Piazza del Plebiscito and Piazza della Morte in order to meet the need for rapid parking for specific uses of public space. Finally, all the architectural barriers have been eliminated, allowing a unitary use and perception of public space. In this way the urban space lends itself to a diversity of functions, including, for example, the possible pedestrianisation of the Piazza delle ErbePiazza della Morte axis or of the system of the three squares, Piazza delle Erbe-Piazza della Morte-Piazza Fontana Grande, in particular periods of the year (i.e. Christmas, Easter, Summertime etc) (Figure 17).

For lighting improvement, a system has been designed on three different levels. Firstly, it directly functions as a contributor to the liveability of the public space by paying particular attention to its widespread graduality. Secondly, it is aimed at the calibrated lighting of the main monuments, such as palaces and fountains. Thirdly, it is aimed at the readability of the new urban environment through "mark steps" (in correspondence with dehors), for example, under-bench LEDs, low lighting for water and trees. In this way, each of the squares offer during night use different possibilities to the end users. Various perspectives have been emphasized and curated as part of the urban environment in a natural and dynamic way.

Last but not least, as for the dehors the design choice was to minimize their visual impact using light shaped Corten elements for chairs and tables, furnishing elements, information panels and so forth. 


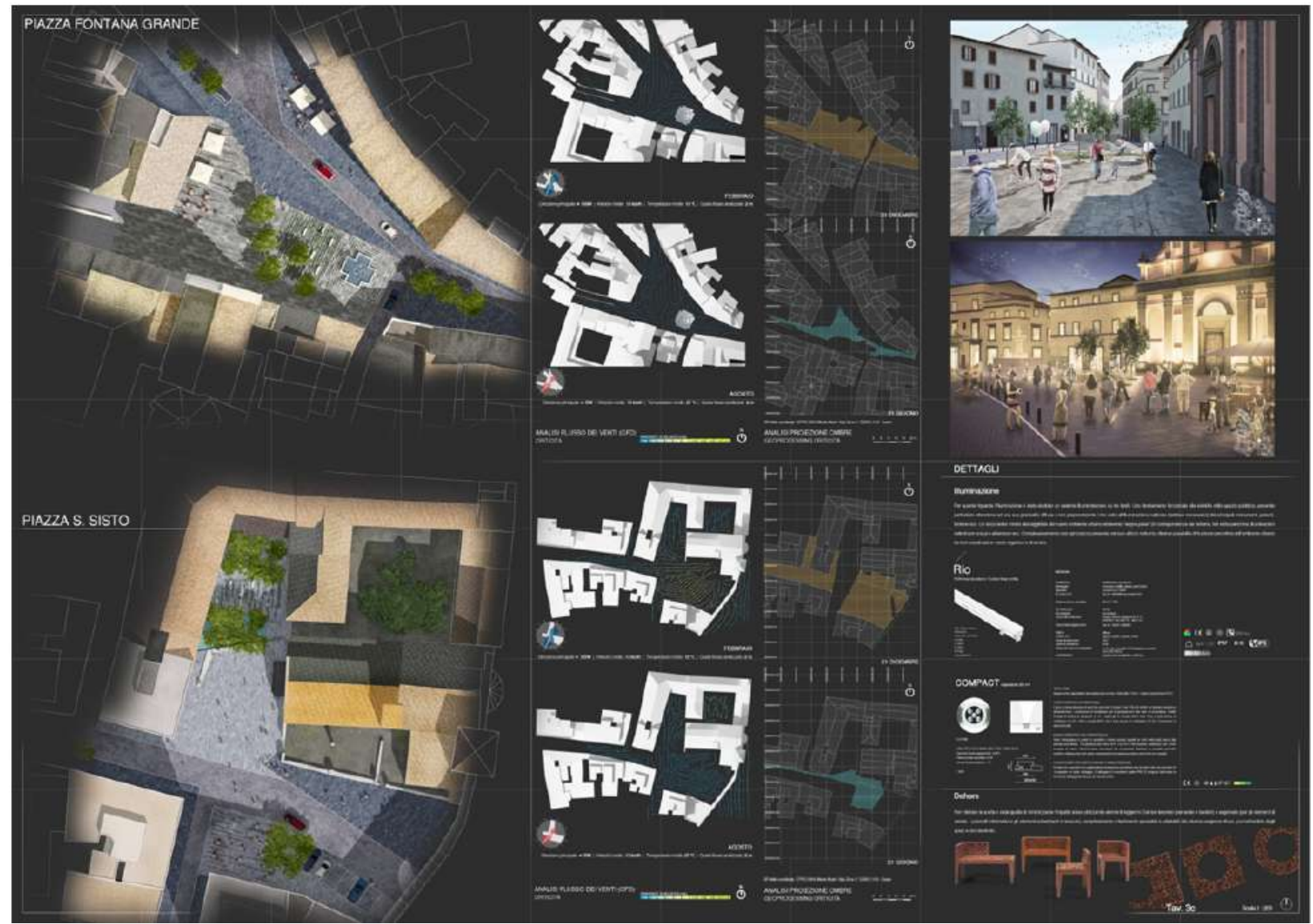

Figure 16. Piazza Fontana Grande (above) and Piazza San Sisto (bottom): Architectural project and Environmental Analysis (Source: M. Maretto)

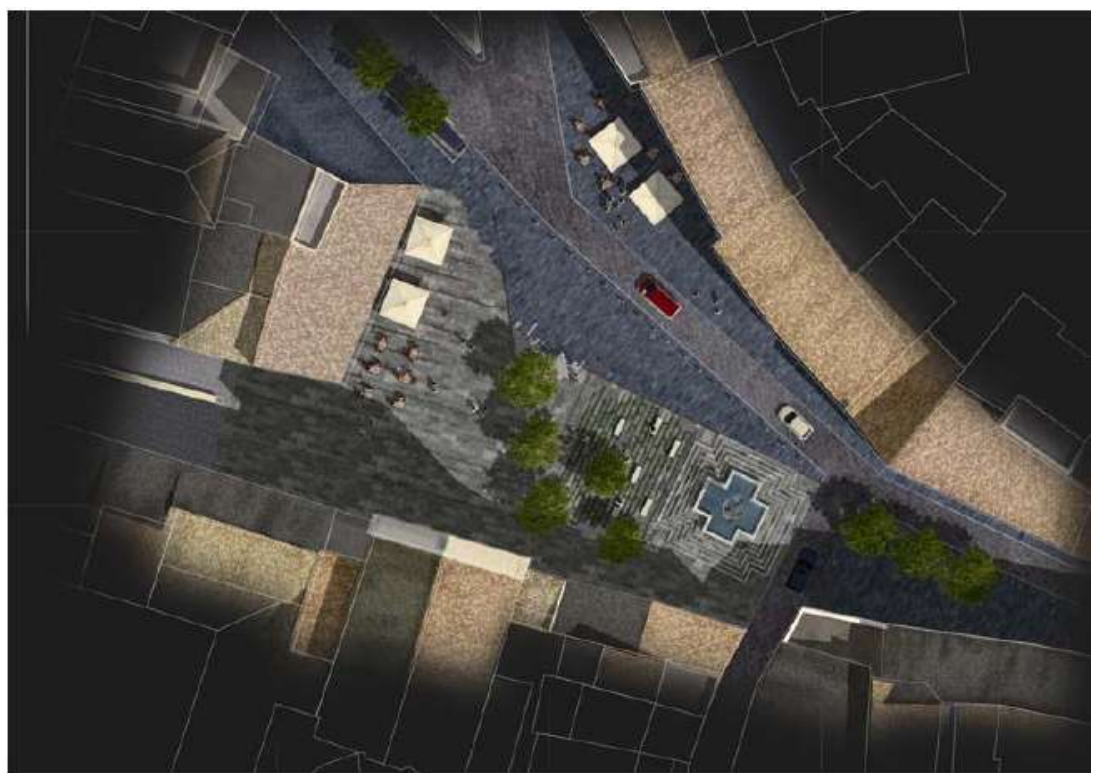

Figure 17. Piazza Fontana Grande, detailed view. ${ }^{4}$ (Source: M. Maretto)

\footnotetext{
${ }^{4}$ The design theme is characterized by the preliminary need to transform Piazza Fontana Grande into a real square. The presence of the important Matrix axis of Via Cavour, in fact, reduces its formal
} 


\section{Conclusion}

As mentioned in the introduction, the city is a complex organism made out of "fabrics". The social, economic and cultural fabric finds their dynamic expression in the physical form of each of the seven public spaces. They are a witness of different levels of relationships, change over time, both material and immaterial. The main task of architecture is then, in our opinion, to understand these "links" (and the processes that underlie them) by providing the physical conditions for their development within a shared value system.

The experience on the seven squares in the historic centre of Viterbo allowed us to develop and deploy a methodology aimed at the three fundamental ambits that characterize a public space. First, the physical one of architecture that defines it on the perceptive level (the "hardware"); second, the immaterial one of those who live and use the space every day (the "software"). And the third, the environmental one that covers everything and influences everything (the "environment"). For these reasons different urban morphology tools (including the Flows Mapping) have been combined with those of human behavior analysis within a specific public space and with the lasted available environmental analysis tools. Overall, the three components have interacted surprising well in synergy largely due to the use of GIS. The environmental attributes were constantly superimposed on the pedestrian flows to understand their different degrees of interaction while the "form" of the spatial envelope, their hierarchies, axes, volumetric data and identity values were constantly verified in relation to the changes of the first two. All of this has made possible, in our opinion, to design living spaces that were, at the same time, aware and respectful from the point of view of the identity, efficient from an energy point of view but also open to maximum flexible to the natural evolution of the ever evolving conditions of the city uses.

perception and hierarchizes its use. Nevertheless, it is a strongly nodal square, third as Value of Nodality in the hierarchy of the historical center of Viterbo. It too is characterized by the presence of a church and an important historical fountain which, in this case, is the theme of the square. The analysis of pedestrian movement flows shows that, alongside a strong viability of the Via Cavour axis, a large part of the stay happens, randomly, between the church, the fountain and some shops located on the left side of the square. The right side, despite the consistent flow of pedestrian passage, does not allow any pause remaining strongly hierarchical. The environmental analysis shows, instead, as main critical points a strong summer sunshine and the cold winter winds towards North-South. In order to give greater perceptive unity to the space, we first thought of expanding the sidewalks of Via Cavour, creating a sort of "squarepasserby" in dark basalt with thin lines of Corten to characterize (as in the other squares) the stopover areas at the service of commerce (non-existent today). This part was then integrated with a rest area, in clear basalt and grassy lines, placed in front of the large fountain, acting as a hinge between the squarepasserby and the churchyard. The presence of new trees has finally allowed to protect the square from excessive summer sunshine and winter breezes, leaving also the warm east-west summer winds which, reduced in intensity and together with the fountain, can perform an effective refreshing action. Once again, the morphological investigation and everyday use of public spaces, together with an accurate environmental analysis, have been the basis for the urban project. 


\section{References}

Aida, M. (I 982), Urban albedo as a function of the urban structure-model experiment, Boundary Layer Meteorol 23, 405-4I3.

Akbari, H., Pomerantz, M., Taha, H. (200I), Cool surfaces and shade trees to reduce energy use and improve air quality in urban areas, Solar Energy 70, 295-310.

ASHRAE (2004), Standard 55-Thermal Environmental Conditions For Human Occupancy, ASHRAE Standards Committee.

Cutler, T. ( 2008), The role of precincts in innovation systems. There's no place like a precinct. An overview, Available at:

https://www.cutlerco.com.au/activities/speeches/09_speeches/precincts_and_innovation_ov erview.pdf

Doulos, L., Santamouris, M., Livada, L. (2004), Passive cooling of outdoor urban spaces. The role of materials, Solar Energy 77 (2), 23 I-249.

Duarte, D., Shinzato, P., dos Santos Gusson, C. \& Abrahão Alves C. (20I5), The impact of vegetation on urban microclimate to counterbalance built density in a subtropical changing climate, Urban Climate 14, 224-239.

Erell, E., Pearlmutter, D. \& Williamson, T. (20I I), Urban Microclimate: Designing the Spaces between Buildings, London, Earthscan.

Fanger, P.O. (1970), Thermal comfort. Analysis and applications in environmental engineering, Copenhagen, Danish Technical Press.

Gagge, A.P., Stolwijk, J.A.J. \& Nishi, Y. (I 97I), An effective temperature scale based on a simple model of human physiological regulatory response, ASHRAE Transactions 77, 247-257.

Gaitani N., Mihalakakou G. \& Santamouris M. (eds.) (2007), On the use of bioclimatic architecture principles in order to improve thermal comfort conditions in outdoor spaces, Building and Environment 42, 317-324.

Gehl, J. ( 1987), Life between buildings, using Public Space, New York, Van Nostrand Reinhold.

Gherri, B, Maretto, M., Guzhda, A., Motti, M. \& Zannetti G. (2018), Early-Stage Environmental Modelling: Tools and Strategies for Climate Based Design, I3th Conference on Advanced Building Skins, Bern.

Givoni, B. (1998), Climate Considerations in Building and Urban Design, New York, Van Nostrand Reinhold.

Gomez N. (2010), Microclimatic study of the space between buildings. Case: Urban housing developments in Maracaibo, Revista Tecnica, Facultad de Ingenieria, Universidad del ZuliaLUZ.

Guidoni, E., Armati, C., Romaniello, L. (2006), Viterbo Medievale. Pianta della città murata intorno al I 462, Roma, Kappa.

Gulyás, Á., Unger, J., \& Matzarakis, A. (2006), Assessment of the microclimatic and human comfort conditions in a complex urban environment: Modelling and measurements, Building and Environment $4 \mathrm{I}(\mathrm{I} 2), \mathrm{I} / \mathrm{I} 3 \mathrm{I}-\mathrm{I} 222$.

Humphreys A.M., Nicol J.F. (2002), The validity of ISO-PMV for predicting comfort votes in every-day thermal environments, Energy Buildings, 34.

ISO (1994), ISO 7730 - Moderate thermal environments - determination of the PMV and PPD indices and specification of the conditions for thermal comfort. International Organization for Standardization.

Kinouchi, T. (200I), A study on thermal indices for the outdoor environment, Tenki 48, 66I-67I (in Japanese with English summary).

Levi-Strauss, C. (1955), Tristes Tropiques, Paris, Librairie Plon.

Marat-Mendes, T. (2013), Sustainability and the study of urban form. Urban Morphology 17 (I), 297-318.

Maretto, M. (2019), London Squares. A study in landscape. Rome-Milan, Franco Angeli. 
Maretto, M. (2018), Teaching Urban Morphology in a Sustainable Perspective, in Oliveira, V. (ed), Teaching Urban Morphology, Springer International Publishing, Cham, 23I.

Maretto, M. (20I4), Sustainable urbanism: the role of urban morphology, Urban Morphology 18 (2), I63-I64.

Maretto, M. (20I2), Ecocities. II progetto urbano tra morfologia e sostenibilità, Rome-Milan, Franco Angeli.

Maretto, M. (2008), Il Paesaggio delle differenze, Pisa, ETS Edizioni.

Matzarakis, A. \& Amelung B. (2008), Physiological Equivalent Temperature as Indicator for Impacts of Climate Change on Thermal Comfort of Humans. In: Thomson M.C. et al. (eds.), Seasonal Forecasts, Climatic Change and Human Health, Springer Science + Business Media B.V. I6I-I72.

Matzarakis, A., Mayer H. \& Iziomon M.G. (1999), Applications of a universal thermal index: physiological equivalent temperature, International Journal of Biometeorology 43, 76-84.

Morini, E., Touchaei, A.E., Castellani, B., Rossi, F. \& Cotana, F. (2016), The Impact of Albedo Increase to Mitigate the Urban Heat Island in Terni (Italy) Using the WRF Model, Sustainability 8(10), 999.

Naboni, E. (20I3), Environmental simulation tools in architectural practice. The impact on processes, methods and design, PLEA2013 - 29th Conference, Sustainable Architecture for a Renewable Future.

Nikolopoulou, M., Baker N. \& Steemers K. (200I), Thermal comfort in outdoor urban spaces: the human parameter, Solar Energy 70 (3).

Pijpers-van Esch, M. (20I5), Designing the Urban Microclimate, Delft. Delft University of Technology.

Pizarro, R. (2009), Urban Form and Climate Change, In: Davoudi, S., Crawford J. \& Mehmood, A. (eds.), Planning for climate change: Strategies for mitigation and adaptation, London, Earthscan Ltd.

Santamouris, M. (ed) (200I), Energy and Climate in the Urban Built Environment, London, James \& James Science Publishers.

Santamouris, M., Synnefa, A., Kolokotsa, D. \& Dimitriou, D. (2008), Passive cooling of the built environment - use of innovative reflective materials to fight heat islands and decrease cooling needs, International Journal of Low Carbon Technologies 3, 7I-82.

Santamouris, M., Synnefa, A. \& Karlessi, T. (20II), Using advanced cool materials in the urban built environment to mitigate heat islands and improve thermal comfort conditions, Solar Energy 85, 3085-3102.

Synnefa, A., Dandou, A., Santamouris, M., Tombrou, M. \& Soulakellis, N. (2008), On the use of cool materials as a heat island mitigation strategy, The Journal of Applied Meteorology and Climatology 47, 2846-2856.

Taha, H. (1997), Urban Climates and Heat Islands, Albedo, Evapotranspiration, and Anthropogenic Heat, Energy and Buildings 25 (2).

Taha, H., Sailor, D. \& Akbari, H. (1992), High albedo materials for reducing cooling energy use, Berkeley, Lawrence Berkeley Lab Rep. 3I72I.

United Nations, Department of Economic and Social Affairs, Population Division (2019), World Population Prospects 2019: Highlights. 